\title{
MIGRACIÓN Y DEPORTACIÓN
}

Migration and deportation

Hna Valdete Wilemann ${ }^{1}$

La migración, como toda manifestación social, tiene comportamientos cambiantes en el tiempo, los cuales se ven influenciados por diferentes causas, hechos y factores. En Honduras la migración tiene como factor relevante los problemas económicos del país, ya sea por la pobreza, por la falta de empleo o por las situaciones de inseguridad social, y la reunificación familiar.

En los últimos 3 años se nota que muchas personas y familias son obligadas a desplazarse de su lugar de origen a otro barrio, comunidad, departamento, para salvaguardar su vida, y que por haber agotado estas opciones, se ven forzados a salir de su país. Si bien es cierto que la migración tiene como factor relevante los problemas económicos y el bienestar social, sin embargo, a cada día vemos nuestra gente salir, no con libertad de decisión, sino como única alternativa de sobrevivencia.

Estados Unidos ha implementado medidas para controlar el ingreso de migrantes a su país, asegurando más sus fronteras, asignando recursos económicos a países que garanticen reforzar sus fronteras como México y Guatemala. Con estas medidas aumentan las deportaciones, especialmente desde México, con especial atención a la repatriación de menores.

A pesar de todas estas estrategias, los hondureños siguen saliendo del país, vendiendo sus tierras para recoger dinero y pagar el viaje, exponiéndose a muchos riesgos. En consecuencia de lo expuesto anteriormente, es que cada día más y más llegan personas en calidad de deportados, ya que la mayoría de las personas que migran lo hacen sin reunir los requisitos para ingresar de forma regular a otros países y, si ingresan de forma regular, muchos no realizan su trámite para arreglar su status migratorio y lograr así quedarse en el país de destino.

\footnotetext{
1 Misionera Scalabriniana, Directora del Centro de Atención al Migrante Retornado. Honduras.
} 
En el año del 2015, el Centro de Atención al Migrante recibió por vía aérea desde los Estados Unidos a 19.320 personas deportadas:

"Tuve que vender mis tierras para recoger dinero y pagar un coyote que me ayudara a cruzar al norte $y$, ahora vengo sin nada y no tengo donde ir". "En México tres mexicanos me robaron la mochila donde tenía mis ropas y un par de tenis que me habían regalado. Me golpearon. Solo recuerdo que fue como a las 3 de la tarde. A las 4 de la mañana me desperté y no sabía dónde estaba y ni que me había pasado. Poco a poco logre recordar todo; en la ciudad de Nueva Loredo hacia Tamaulipas camine 5 días a pie para llega al Rio Bravo. En el primer intento fuimos secuestrados y solo porque Dios es grande es que escapamos. Esa tarde fue desesperante: llegamos al Rio Bravo y cuando lo estábamos cruzando, el rio nos llevaba, o sea, arrastraba, quede trabado en una rama que había en la orilla del rio. El rio arrastraba Fernando, el que iba conmigo, el me abrazo para que el agua no se lo llevara y con mucho esfuerzo logramos salir del rio. Salimos sin nada, solo con ropa interior, sin calzados, con hambre, con sueño. Poco minutos después fuimos capturados por los de la migra y nos deportaron. $\mathrm{Ni}$ recuerdo cuantos días estuve preso. Me deportaron por agua caliente y hasta hoy es que me comunique esposo e hijos, después de 6 meses de aventura. No Volveremos a salir de forma irregular. Hoy con mucho esfuerzo trabajo en el campo sembrando maíz. Gano poco pero tengo mi familia junto a mi".

Estas son unas de las tantas historias que se escucha de los que dejan todo en busca de un sueño y son enviados de regreso a su país con manos vacías y esperanzas rotas.

\section{Centro de Atención al Migrante Retornado}

El Centro de atención al Migrante Retornado es una iniciativa de las Hermanas Scalabrinianas en asocio con la Organización Internacional para las Migraciones (OIM). El objetivo del Centro es brindar asistencia inmediata (alimentación, transporte, hospedaje, salud) a las personas que son retornadas en calidad de deportados, vía aérea, desde Estados Unidos, y ayudar a la reinserción social de los mismos, mediante capacitaciones, talleres motivacionales y bolsa de empleo.

En el año 1992 se registran las primeras deportaciones vía aérea desde Estados Unidos, las cuales se hacían de forma clandestina en los vuelos comerciales. En el año de 1997 nace el servicio de atención al migrante, en el pasillo del antiguo aeropuerto de Tocontín - Tegucigalpa, por iniciativa de la Pastoral de Movilidad Humana/Caritas, coordinada por las Hermanas Scalabrinianas. En los años de 1998 y 1999 se siguió brindando la atención a los migrantes en una oficina en el aeropuerto. En el año 2000, con el programa de deportación masiva de Estados Unidos, la Embajada Norte Americana en 
Honduras, a través de la Organización Internacional para las Migraciones (OIM), construyó oficinas en el aeropuerto de Tocontín en Tegucigalpa y en el aeropuerto Ramón Villeda Morales de San Pedro Sula, para el funcionamiento de los Centros de Atención al Migrante Retornado - CAMR.

En los años siguientes se contó con el apoyo de varias organizaciones: Embajada de Estados Unidos, Catholic Relief Service, Cordaid, Iglesia Católica de Texas y Trocaire, hasta que el Gobierno de Honduras, a través del Ministerio de Relaciones Exteriores, asume el presupuesto del Centro. El Centro pasa a ser coordinado directamente por las Hermanas Scalabrinianas con el apoyo del Gobierno de Honduras. A partir del año 2013 empieza a funcionar solamente el Centro en San Pedro Sula, debido a que los vuelos de los deportados son direccionadas a esta ciudad.

\section{Apoyando a los Migrantes}

Actualmente el Centro cuenta con dos consultorios médicos, oficinas para la protección al migrante, asesoría legal, oficinas del Registro Nacional de las Personas, asistencia psicológica, ofertas gubernamentales (secretaria de trabajo, INFOP), cabinas para chequeo migratorio, sala de espera para los familiares.

Cada migrante recibe gratuitamente alimentación, kit de aseo personal, llamada telefónica, camiseta, bolso. Todo eso es posible gracias a diferentes organizaciones que se solidarizan con los migrantes, a través de donaciones, para que las personas puedan ser recibidas con dignidad. También se les apoya con el boleto del autobús para que puedan llegar a sus hogares.

Contamos con alianzas de los call center quienes ofrecen oportunidad de trabajo para los que son bilingües (inglés/español), y la Secretaria de Trabajo por medio del proyecto "con chamba vivís mejor". Son direccionados a puestos de trabajo disponibles en diferentes empresas y los menores de 28 años, a través del asocio con la Asociación Menonita, reciben capacitaciones.

La mayoría de los migrantes están entre las edades de 18 a 35 años. Lamentablemente es nuestra juventud la que cada día deja sus estudios buscando migrar hacia otros países tales como: Estados Unidos, España, Belice. Son miles de situaciones las que cada día enfrentan nuestra sociedad a causa de la violencia, inseguridad y desempleo, donde se vuelven vulnerables nuestros jóvenes, adolescentes y niños (as): "Los miembros de las pandillas me buscaron para vender droga y como me negué, ahora me buscan para matarme, por eso decidí salir del país y abandonar a mi familia".

\section{Algunos resultados}

- Las instituciones gubernamentales, no gubernamentales, nacionales e internacionales, han reconocido y respetan la misión que las Hermanas Scalabrinianas realizan con la población migrante, por más de 25 años. 
- En la actualidad se logró emplear a más de 500 migrantes en diferentes empresas, también muchos empezaron su propio negocio.

- Muchos jóvenes han retomado a sus estudios y dicen que no piensan en volver a enfrentar los peligros de la ruta migratoria.

- Se han creado programas para concientizar a la población sobre la migración y la deportación, logrando disminuir la creencia de que los migrantes son personas que se van huyendo por haber cometido algún delito.

Se busca tratar a cada persona que llega deportada como nuestro hermano y hermana, viendo en cada uno de ellos el rostro del Cristo peregrino, recibiéndolo con amor y respetándoles como un hijo de Dios que necesita ser escuchado, respetado y admirado por su valentía en enfrentar los peligros en la ruta migratoria, con la esperanza de alcanzar sus sueños.

Son muchas las personas que regresan a Honduras en calidad de deportados. Vemos que cada uno refleja en su rostro tristeza y desesperación, sus sueños y esperanzas han quedado para atrás. Nosotras ponemos un granito de arena recibiéndolos con cariño y extendiéndoles una mano amiga, apoyando en sus necesidades inmediatas y con la esperanza que sus familiares les esperen con los brazos abiertos y les brinden el apoyo que necesitan. 